\title{
Anxiolytic Benefits of Exercise Classes for Mothers
}

Currie $\mathbf{J}^{*}$

Health and Physical Education, University of Technology Sydney, Australia

*Corresponding author: Currie J, Health and Physical Education, University of Technology Sydney, Australia, Tel: + 61295145192; E-mail: Janet.Currie@uts.edu.au Received Date: August 7, 2018; Accepted Date: August 16, 2018; Published Date: August 23, 2018

Copyright: @2018 Currie J. This is an open-access article distributed under the terms of the Creative Commons Attribution License, which permits unrestricted use, distribution, and reproduction in any medium, provided the original author and source are credited.

\begin{abstract}
Objective: The importance of women accessing physical activity has been shown in the literature as being even more critical for wellbeing following birth of a child. As there is scant research available specifically purporting the mental health benefits of exercise classes, this paper examines the anxiolytic or anxiety-reducing benefits gained from involvement in a 3-month, twice-weekly group low-impact exercise class program for a group of mothers $(n=21)$.
\end{abstract}

Method: Quantitative data were obtained by measuring acute pre and post-changes (or pre and post-60 minutes interval for the exercise group and a non-exercising control) in the level of state anxiety (i.e. how you feel 'right now'), through the Spielberger et al. State Anxiety Inventory (STAI).

Results: The mean state anxiety levels experienced pre and post-activity showed a significant change (decrease) in exercising mothers as compared to non-exercising mothers at both Week 1 (Measurement $A$ ) and at 12-weeks (Measurement B) $(p<0.05)$.

Conclusion: Mothers are able to experience a decrease in acute anxiety following participation in exercise classes. Further strategies that allow for enhanced access and the continuation of care of children or relatives by others while the mother takes time out for health promoting exercise for leisure will need to be developed.

Keywords: Mothers; Anxiety; Exercise classes; Stress; Women's fitness; State anxiety inventory; Anxiolytic

\section{Introduction}

Individual health includes maintaining a sense of balance between the physical, emotional/mental, social and spiritual aspects of our wellbeing. These areas are interrelated and interdependent [1]. As the pace of life in Western society continues to accelerate, gaining access to quality leisure becomes even more important from a health point-ofview [2,3]. More recently, research recommends leisure pastimes as being a means of coping with such daily stress. Not only has exercise been clinically proven to improve mood or lower depressive and anxiety states, recent research has demonstrated that exercise might also help us to engage in more positive things, thereby improving our overall lifestyle and perceived satisfaction with quality of life [4-7].

Even perceiving one's self as being physically active compared with peers has been concluded as an important factor related to health status and predicted mortality. For example, in Zahrt and Crum's major study, individuals who perceived themselves as less active than others were up to $71 \%$ more likely to die in the follow-up period than those who perceived themselves as more active, even after accounting for the effects of actual physical activity levels and other known determinants of mortality [8]. Therefore, it's not surprising participation in exercise is often recommended for enhancing wellbeing [9-12]. Mothers have been identified as a group that could significantly benefit from physical activity interventions for enhancing social and emotional wellbeing, particularly stress levels $[12,13]$. However, mothers perceive more barriers to accessing exercising than women without children do [13-15].
The combination of little control and attempting to be on-call meeting the relentless demands of caring may account for the stressfulness of these roles [15]. One of the major shocks for mothers after the birth of a child is that their own needs for time, space and nurture have suddenly become secondary to the baby's needs [16]. In a vicious circle, women also involved in outside employment often experience "role overload" which is associated with negative health outcomes including elevated levels of stress, depression, and anxiety $[17,18]$. Lack of time is also the principal and most prevalent reason given for an inactive lifestyle $[9,13,19]$. With many mothers reporting high levels of stress and constraints in managing their busy lifestyles, the importance of them being able to access active leisure becomes even more critical for maintaining individual health and wellbeing $[18,19]$.

A paradox exists in that while mothers value the role of physical activity as part of their wellbeing, they report on finding it difficult to access or find suitable formats $[18,20]$. One active leisure activity that has been proposed as a potentially more convenient and accessible option for mothers is exercise classes $[9,12,18]$. Its perceived benefits may vary across age groups, but overall women state perceived enjoyment from the 'feel good' aspects involved from their exercise class participation [21]. However, there is scant evidence-based research that has been published on the benefits of exercise class participation for women. Most reports are typically anecdotal in nature, or promoted through the mass media [22,23]. Health care providers prefer recommending the most reliable and evidence-based forms of exercise available. Likewise, participants themselves would benefit from understanding the mental health efficacy associated with a particular activity. With fitness classes and gym being the second most 
Page 2 of 5

commonly participated recreation activity undertaken by women in Australia after walking, it is surprising that so little research has been undertaken regarding its perceived benefits as a potential leisure activity $[24,25]$. Therefore, the purpose of this study was to discover whether participation in exercise classes is reported by mothers as positively impacting on stress levels.

\section{Method}

\section{Research design}

As the study aimed to examine any potential anxiolytic or anxietyreducing phenomenon associated with exercise class participation, a group of exercising mothers and a non-exercising control group both completed inventories intending to evaluate reported measures of individual anxiety levels. A quasi-experimental research design was implemented using non-randomised group pretest-posttest results, with 'treatment' consisting of a 12-week, low impact group exercise class program. STAI Measurements were examined pre and postactivity at Week 1 and Week 12 to assess consistency and also note any possible changes due to cumulative adaptation.

\section{Sample}

A sample of convenience of exercising mothers $(n=21)$ volunteered to take part while the non-exercising control group of mothers $(n=21)$ were recruited from those mothers who were attending local health centers with their child. Hence the self-volunteering mothers in the exercise group may have been more motivated to be involved in exercise and lowering their stress compared with the control group of mothers. All women in the sample lived in the same metropolitan region of Sydney, NSW, Australia. The mean age of the exercise group was 37.3 years and the non-exercise group 29.2 years. The exercising mothers had a mean number of 2.2 children each, and the nonexercisers 1.4 children each. The mean age of the exercising mothers' children was 10.4 years the non-exercising group's children only 3.6 years of age. So, while on average the exercising mothers had more children to care for, a younger child could be considered more demanding in terms of the amount of care required [26]. Thirteen of the exercising mothers were involved in outside employment compared with only three in the non-exercising group. Respondents had to meet the inclusion criteria of being a mother of one or more children, identify as well, and living in the Warringah area of Sydney, Australia. Only mothers who did not withdraw from the study or miss a session were included in the results. The control group contained 21 mothers who did not engage in any exercise for the duration of the 12 week program.

\section{Exercise treatment}

The exercise classes included 60-minute, moderate intensity, LowImpact aerobics or group exercise classes conducted twice a week, for 12 weeks in a local community hall. 'Low-impact' means that at least one foot is always landed and weight-bearing on the ground at any one time, so the class involves mainly stepping or walking movements with no running or jumping. The format consisted of a gradual warm-up, rhythmic movements or steps conducted in the upright or standing position, muscle conditioning exercises conducted on the floor such as leg raises, abdominal exercises, followed with a final cool down and stretching phase.

\section{Procedures}

Results were obtained by administering the State Anxiety Inventory Form Y-1 (STAI) to the two groups of women [27].

The two groups being assessed were:

- Exercise Group-those who participated in a regular twice-weekly exercise program and completed all sessions for twelve weeks $(\mathrm{n}=21)$; and

- Non-Exercise Group-those who did not participate in an exercise program $(n=21)$.

The STAI is a 20-item inventory or survey measurement tool able to be self-administered to reliably detect any changes in a person's level of state or acute anxiety, for how stressed s/he is feeling, 'right now'. State anxiety is the intensity of any unpleasant emotional state of how we may be experiencing or responding to stressors at a given point in time, characterised by the degree an individual perceives any feelings of tension, apprehension, nervousness or worry. Each Likert-scale response (1-20) attracts a score of 1-4, with 20 points the lowest and 80 points the maximum possible. A decrease in the STAI post-activity indicates a reduction on anxiety. Therefore, it is the negative change that is able to indicate whether an activity is anxiolytic or not.

The STAI is the most commonly used instrument in exercise studies for measuring anxiety levels and has been documented as a reliable, valid and sensitive indicator of changes in state anxiety [28]. It was explained to respondents that the inventory required them to report how they felt 'right now....at this moment'. Each member of the two groups in the sample answered the STAI questionnaire before and after an activity of one hour's duration. For example, members of the exercise group were given the inventory to answer before commencing the exercise class, and then immediately afterwards for the researcher to notice the difference in scores and therefore define the respondent's acute response/change. Members of the non-exercise group, however, were given the inventory to answer immediately before and after a non-exercise related activity such as household work. An important factor which does reflect positively on the equivalence of the two groups is the 'baseline' STAI scores of the two groups of mothers as they entered the program. The mean STAI scores of the recorded at Week 1 were:

- Exercise Group: 35.38

- Non-Exercise Group: 36.05.

The first occasion that the STAI was administered is illustrated in the results as 'Measurement A'. The inventory was distributed again after a 12-week period to members of each group to gauge consistency in responses. This is illustrated in the results as 'Measurement B'.

\section{Data Analysis}

To test the significance of the changes in mean STAI scores for the two groups of mothers, pre to post activity at the two intervals (Measurements A and B), an independent one-tailed t-test was selected [29]. All data were analyzed using the t-test for independent samples of group from SPSS [30]. For the purposes of this study, a confidence interval of 0.05 was used. The next section presents the results of the inventory measurements of anxiety levels pre and post activity. 
Page 3 of 5

\section{Findings}

The aim of this study is to report on the perceived stress-relieving benefits reported by mothers who have been able to carve time out to participate in exercise classes compared with a group who participated in non-exercise activities. The quantitative results are concerned with any changes in the mothers' STAI inventory scores post-activity compared with pre-activity. The average changes in STAI scores for the exercise groups were -5.76 and -8.00 Measurements $\mathrm{A}$ and $\mathrm{B}$ respectively. However, the average changes for the non-exercise group were +4.81 and +2.52 for Measurements A and B (at Week 1 and 12), respectively. A decrease in anxiety is indicated by a negative figure whereas a positive figure indicates an increase in anxiety. Therefore, the greatest decrement in anxiety pre-post activity was present in the exercise group for Measurements A and B, with the exercise group as a whole achieving decreases in STAI scores of -121 and -168 , for Measurements $\mathrm{A}$ and $\mathrm{B}$. In contrast, the non-exercise participants increased their STAI scores by a total of 101 and 53, for Measurements $\mathrm{A}$ and $\mathrm{B}$ respectively.

The results were tested to see if they were significant using a $95 \%$ confidence interval, and confirmed the hypothesis that mothers who participate in exercise programs experience a significant decrease in stress after exercising compared with mothers who don't exercise. The t-test used was to test the significant difference in scores before and after (exercise/non-exercise) between the two independent groups of mothers. The $t$ values for Measurements A and B were -4.27 and -4.68 respectively. The mean change of -5.7619 (exercising group, 21 cases) compared with 4.8095 (non-exercising group, 21 cases) for Measurement A at .05 level of confidence (for a one tailed t-test) was significant. The mean change of -8.000 (exercising group, 21 cases) compared with 2.5238 (non-exercising group, 21 cases) was also significant for Measurement B, at .05 level of confidence (for a one tailed t-test). The decrease in anxiety post-exercise session was also significant at the $0.0025 \%$ confidence level. Therefore, both measurements $\mathrm{A}$ and $\mathrm{B}$ showed a significant change in exercising mothers as compared to non-exercising mothers $(\mathrm{p}<0.05)$. The factors influencing these results will now be examined.

\section{Discussion}

The reported subjective decrease in stress associated with the class participation may be associated with the general anxiolytic nature of exercise per se [31-34]. According to Johnsgard, exercise can produce a very significant tranquillising effect, which usually lasts for two hours [35]. This may be due to release of endorphins or a simple decrease experienced in overall tension and improved mood [12,35]. If the classes were of too high an intensity, or not well received, the exercise may have led to increases in anxiety, tension and fatigue, suggesting that moderate intensity, continuous aerobic activity may be best [6] Bahrke and Morgan found that less intensive non-exercise activities such as meditation and quiet rest can also achieve reductions in state anxiety [32]. However, these methods may not be as practical or readily achievable and convenient for the mother, unless she has individual childcare organised and a quiet space available. Nonexercise activities also don't provide the fitness-related benefits of exercise, such as increased cardiovascular capacity, or improvements in strength or muscle tone.

The exercising group's positive experiences regarding reported decreased stress, as reflected in their STAI, may have been moderated via the stress-reducing mechanism of social support [35-38]. Access to social support is associated with psychological wellbeing and a lower probability of physical illness, however, social isolation is associated with psychological distress and postnatal depression [39,40]. The nonexercising mothers may have felt more anxious if they considered themselves to be isolated in a negative way at home. These buffering effects may occur only when the kinds of support available match the needs elicited by the stress a person is experiencing. For instance, the exercisers may have felt less stressed due to the availability of childcare and having a break. However, perhaps the class wouldn't have been so anxiolytic if participants found the other mothers unfriendly or the instructor and atmosphere unwelcoming.

The various modes of social support available to the exercising group of mothers in this study able to impact positively on wellbeing included [41]:

- Esteem support: Includes mothers talking to each other and ventilating feelings;

- Status support: Other mothers sharing a common bond.

- Informational support: Exchanging and sourcing information and ideas.

- Instrumental support: Provision of free childminding and parking.

- Social companionship.

- Motivational support.

A greater proportion (18 out of 21) of the mothers in the nonexercising (control) group were involved in unpaid, full-time home duties. Unpaid work includes household work (such as cleaning, washing, home maintenance), caring for family members, and volunteer community work. Almost half of the exercising mothers were involved in part- or full-time outside paid employment, and the rest in full-time home duties. The fact that a greater proportion of the mothers in the non-exercising group were involved in 'unpaid' work or perhaps feeling somehow more constrained by this feature [42], may have negatively influenced their STAI results. The non-exercising group may not have been able to relieve their anxiety as effectively the exercisers because they felt more trapped in their role on the occasions the STAI was completed. There are many reasons for lower rates of physical activity experienced by women [43]. However, it is mainly due to them reporting having less time and ironically, feeling too tired due to greater responsibilities for housework and childcare [19].

\section{Limitations to interpretation of the findings}

There are numerous limitations to interpreting the study's findings. Perhaps the largest limitation is the fact that the exercise group volunteered to exercise, rather than being randomly assigned to exercise/non-exercise. However, this may be attributed to the local community, low-cost nature of the exercise setting used for the study and its sample of convenience. The Spielberger et al. STAI purports to measure the level of state anxiety in an individual, that is, how anxious a person feels 'right now, at this moment' [27]. It is therefore situationspecific and sensitive to changes in the level of tension, nervousness, worry and anxiety present in a person over time. However, it does rely on the respondent's honesty and integrity. Respondents have to select only one answer or position on the Likert Scale out of the four possibilities available for each question, and they may not like to 'pigeon hole' or label themselves in this way.

Although the STAI can act like a temperature gauge in noting if a person is either relatively relaxed or highly stressed, it cannot provide the reasons why a person feels that way. Therefore, people can feel 
stressed for different reasons, but this won't be detected or included in the STAI score results. The STAI utilised in this study may have been insensitive to monitoring particular aspects or the magnitude of the respondents' stress experience. The mothers may have found certain questions inappropriate to their own individual situation, or that more applicable categories able to capture how they were feeling were absent from the inventory. Some symptoms that were experienced by the mothers in this study may not be highlighted or available on the anxiety inventory. If a symptom seems commonplace to the mother, for example feeling tired, it may also be considered as normal and therefore not defined as illness or stress. Some of the mothers who may have been 'rushed' or 'tense and jittery' on the day of the measurement may have been so used to feeling these symptoms that they believed they were part of feeling normal as a mother and their score was lower due to under-representation or desensitisation. Consequently, these symptoms may have been played down in their own anxiety inventory results. While the employment status of respondents did not change during the study, mothers considering themselves to be unemployed or those experiencing factors considered beyond their own control, may have had their high stress levels under-represented. Respondents may have also answered some questions according to what is culturally acceptable for a 'good mother' to be like.

If a mother is too 'jittery' (Question 13, STAI), 'frightened' (Question 9, STAI) or 'indecisive' (Question 14, STAI), then this may indicate weakness. Individuals with higher self-esteem may have been more truthful in their responses. State levels of anxiety are influenced by a person's trait or stable individual differences in anxiety proneness plus their interpretation of the situation they are experiencing; is it considered threatening, dangerous or worrying, for example. Those mothers with a normally low degree of trait or general personalitytype level of anxiety might have recorded lower state responses to the STAI. It is of concern that STAI measurements may be biased by having high mean trait levels existing within a sample. Future research might incorporate the impact of individual levels of trait and state anxiety, motivation, self-efficacy, resilience, responses to class-specific influences such as music, and the effect of socio-economic factors on results. Due to the small numbers involved and local nature of the investigation, the findings aren't generalizable. However, they do help point to initial, quantifiable evidence suggesting that exercise classes may be of specific mental health benefit for mothers, helping inform and offer efficacy to program recommendations. All respondents taking part identified as 'well' and not experiencing illness or disease, however it was not discovered if any mother's responses at the time of completing the inventory was influenced by medication or an undisclosed mental condition. Accessing a meaningful, fulfilling and positive leisure lifestyle for one's self is an important component of health promotion and maintenance of wellness. The basic characteristics of this leisure experience may include enjoyment, relaxation, intrinsic motivation, commitment, control, challenge and freedom of choice. The aerobics classes in this study could be thought of as a leisure experience if the mothers thought of them as pleasurable, self-determined, yet enjoyable, and an area where they felt competent and in control. This would not be possible if the instructor's style was too autocratic, if they did not design the program to meet the needs of the clientele, or if the women felt driven to attend through obligation, rather than pure motivation.

Leisure experiences such as the classes, involving intrinsic motivation of a self-determining nature can result in psychological benefits. Further research is warranted to discover the particular anxiolytic mechanism within the exercise class, such as the music, the time out, the availability of childcare, or aspects of the exercise process itself [41]. It has also not been discovered within the limits of this study if the exercising mothers delegated tasks more often than the nonexercising mothers. This aspect would be worthy of greater investigation in combination with leisure lifestyles. Resistance by mothers in the form of task delegation or rationalization has to ensure that they can participate effectively in leisure activities $[19,44]$. Otherwise mothers may feel too bombarded with work when they return from leisure, or may feel too busy or constrained by housework to be able to afford the time off [43]. Ignoring stress symptoms, or not being able to utilize a coping strategy such as exercise can unfortunately create more distress in the long term [18]. Due to the ethic of care associated with 'good' mothering or possible guilt, some working mothers (both paid or unpaid) may be less willing to take time out to exercise for leisure [45]. Women can find it difficult to plan leisure in advance with any degree of certainty due their caring and housework responsibilities. This pressurizes them into being constantly available and on call to care for others. Some even feel unwilling to relinquish their child-minding duties in order to access leisure time for self, or feel guilty when doing so [19]. As mothers face many barriers to spend leisure time outside the home, much so-called free time for leisure is spent on activities centered around the home or with children present [13]. Health is about helping individuals develop a critical awareness of their situation and enabling them to master their environment to achieve self-determination. When the mothers take time-out to exercise, they can become 'master' of their own environment for a change, even if only for an hour at a time. This is in direct conflict with the view of Condon [46] who stated that women can never fully escape the influence of the socially constructed gender roles that "restrict their freedom of thought, will and action".

\section{Ethical Approval}

All procedures performed in the study involving human participants were in accordance with the institution's ethical standards for the National Statement on Ethical Conduct in Human Research issued by the National Health \& Medical Research Council of Australia.

\section{Conclusion}

The mothers participating in the exercise program achieved significant decreases in acute anxiety compared with those mothers who did not exercise. This conclusion supports the findings of previous qualitative studies $[12,19]$. As a population group however, most mothers potentially miss out on these benefits [20,43]. Mothers usually have limited opportunities for leisure. This may form a barrier to them receiving the consistent mental health benefits that active leisure has to contribute $[19,47]$. Women have identified that physical activity is an important aspect of them maintaining wellness after the birth of a child $[15,19]$. A sense of freedom and control is critical for actual leisure involvement and also for mental health. The anxiolytic benefits gained from participation in exercise classes can assist mothers in managing the stresses of everyday life. Further strategies that allow for enhanced access and the continuation of care of children or relatives by others while the mother takes time out for health promoting exercise for leisure will need to be developed. Taking time out to exercise with childcare available allows a mother to experience a separate space free the usual burdens associated with her role, decrease stress, and promote wellbeing. 
Page 5 of 5

\section{Conflict of Interest}

The author declares no conflict of interest.

\section{Informed Consent}

Informed consent was obtained from all individual participants included in the study.

\section{References}

1. Donatelle RJ (2015) Health: The Basics (11th edn). Pearson, Harlow Essex, UK.

2. Hamilton Smith E (1991) The Construction of Leisure, in BL Driver, P Brown, GL Peterson (Eds), Benefits of Leisure. Venture Publishing, Pennsylvania pp: 445-450 .

3. Mannell RC (2007) Leisure, Health and Well-Being. World Leis J 49: 114-128.

4. Stathopoulou G, Powers MB, Berry AC, Smits JA, Otto MW (2006) Exercise interventions for mental health: A quantitative and qualitative review. Clin Psych: Sci \& Prac 13: 179-193.

5. Strohle A (2009) Physical activity, exercise, depression and anxiety disorders. J Neural Trans 116: 777

6. Steptoe A, Cox S (1988) Acute effects of aerobic exercise on mood. Health Psych 7: 329.

7. Young KC, Machell KA, Kashdan TB, Westwater ML (2018) The cascade of positive events: Does exercise on a given day increase the frequency of additional positive events? Pers \& Ind Diff 120: 299-303.

8. Zahrt OH, Crum AJ (2017) Perceived physical activity and mortality: Evidence from three nationally representative US samples. Health Psychol 36: 1017.

9. Hayosh T (2017) Engagement is serious leisure as practice for coping with the stress of daily life. World Leis J 59: 206-217.

10. Mannell RC, Salmoni AW, Martin L (2002) Older adults caring for older adults: Physically active leisure lifestyles as a coping resource for the health of caregivers. Soc \& Leis 25: 397-420.

11. Elavsky S, McAuley E, Motl RW, Konopack JF, Morquez DX, et al. (2005) Physical activity enhances long-term quality of life in older adults: Efficacy, esteem, and affective influences. Ann of Behav Med 30: 138-145.

12. Currie J (2018) Radical leisure: How mothers gain well-being and control through participation in exercise classes. Common Ground Research Networks, Champaign, IL.

13. Verhoef MJ, Love EJ (1994) Women and exercise participation: The mixed blessings of motherhood. Health Care Women Int 15: 297-306.

14. Welch N, McNaughton S, Hunter W, Hume C, Crawford D (2009) Is the perception of time pressure a barrier to healthy eating and physical activity among women? Pub Health Nut 12: 888-895.

15. Currie J (2008) Conditions affecting perceived coping for new mothers: Analysis of a pilot study, Sydney, Australia. Int J Ment Health Prom 10 34-41.

16. O'Brien W, Lloyd K, Riot C (2017) Exploring the emotional geography of the leisure time physical activity space with mothers of young children. Leis Stud 36: 220-230.

17. Luecken LJ, Suarez EC, Kuhn CM, Barefoot JC, Blumenthal JA, et al. (1997) Stress in employed women: Impact of marital status and children at home on neurohormone output and home strain. Psychosom Med 59: 352-359.

18. Shivakumar G, Brandon AR, Snell PG, Santiago-Munoz P, Johnson NL, et al. (2011) Antenatal depression: A rationale for studying exercise. Depr \& Anx 28: 234-242.

19. Currie J (2004) Motherhood, stress and the exercise experience: Freedom or constraint? Leis Stud 23: 225-242.

20. Currie J (2009) Managing Motherhood: Strategies used by new mothers to maintain perceptions of wellness. Health Care Women Int 30: 653-668.
21. Currie JL (2013) Perceived Benefits of Women's Participation in Exercise Classes. Int J Sport \& Soc 3: 1-7.

22. Carroll W (2017) Benefits of group exercise: My Body + Soul.

23. Veling J (2017) The Benefits of Group Fitness Classes: Active. http:// www.active.com/fitness/articles/the-benefits-of-group-fitness-classes

24. Australian Bureau of Statistics (ABS) (2012) 4156.0-Sports and physical recreation: A statistical overview, Australia, 2012.

25. Choi PYL, Van Horn JD, Picker DE, Roberts HI (1993) Mood changes in women after an aerobics class: A preliminary study. Health Care for Women Int 14: 167-177.

26. Kimmel J, Connelly R (2007) Mothers' time choices: caregiving, leisure, home production, and paid work. J Hum Res 42: 643-681.

27. Spielberger CD, Gorsuch RC, Lushene RE (1983) Manual for the StateTrait Anxiety Inventory STAI (Form Y): ("Self-Evaluation Questionnaire”). Consulting Psychologists Press, Palo Alto, California.

28. Marteau TM, Bekker H (1992) The development of a six-item shortform of the Spielberger State-Trait Anxiety Inventory (STAI) Brit J Clin Psych 31: 301-306.

29. Croucher JA, Oliver E (1979) Statistics: An introduction. McGraw-Hill, Sydney.

30. Norussis MJ (1993) SPSS Inc.SPSS for Windows: Base System User's Guide. SPSS Incorporated, Chicago.

31. Anderson E, Shivakumar G (2013) Effects of Exercise and Physical Activity on Anxiety. Front Psych 4: 27.

32. Bahrke MS, Morgan WP (1978) Anxiety reduction following exercise and meditation. Cog Ther Res 2: 323-333.

33. Salmon P (2001) Effects of physical exercise on anxiety, depression and sensitivity to stress: A unifying theory. Clinical Psychology Review 21: 33-61.

34. Carmeli E (2013) Physical activity reduces stress and anxiety. Aging Sci 2: e108.

35. Johnsgard KW (1989) The exercise prescription for depression and anxiety. Plenum Press, New York.

36. Leach J (2015) Improving mental health through social support: Building positive and empowering relationships. Jessica Kingsley Publishers, London.

37. Lloyd K, Little DE (2010) Self-determination theory as a framework for understanding women's psychological well-being outcomes from leisuretime physical activity. Leis Sci 32: 369-385.

38. Oakley A (1992) Social support and motherhood: The natural history of a research project. Blackwell, Cambridge, Massachusetts.

39. Lawson JS, Callaghan A (1991) Recreating the village: The development of groups to improve social relationships among mothers of newborn infants in Australia. Aust J Pub Health 15: 64-66.

40. Leigh B, Milgrom J (2008) Risk factors for antenatal depression, postnatal depression and parenting stress. BMC Psychiatry 8: 24.

41. Cohen S, Syme SL (1985) Issues in the study and application of social support, in S Cohen \& SL Syme (Eds), Social Support and Health. Academic Press, Florida pp: 3-22.

42. Wanamaker NJ, Bird GW (1990) Coping with stress in dual career marriages. Int J Sociol Fam 20: 199-211.

43. Brown WJ, Mishra G, Lee C, Bauman A (2000) Leisure time physical activity in Australian women: relationship with well being and symptoms. Res Quart Ex Sport, 71: 206-216.

44. Iso-Ahola SE, Weissinger E (1984) Leisure and well-being: Is there a connection? Parks \& Rec 19: 40-44

45. Wearing B (1990) Beyond the ideology of motherhood: Leisure as resistance. J Sociol 26: 36-58.

46. Condon EH (1992) Nursing and the caring metaphor: Gender and political influences on an ethic of care. Nursing Outlook 1: 69-84.

47. Warburton DE, Nicol CW, Bedi SS (2006) Health benefits of physical activity: The evidence. Canad Med Assoc J 174: 801-809. 